\title{
Impact of different pre-treatment strategies on the quality of fatty acid composition, tocols content and metabolic syndrome related activities of Perilla frutescens seed oil
}

\author{
Sasithorn Sirilun ${ }^{1}$, Bhagavathi Sundaram Sivamaruthi ${ }^{1}$, Noppawat Pengkumsri ${ }^{1}$, Manee Saelee ${ }^{1}$, Khontaros Chaiyasut $^{2}$, \\ Nucharee Tuntisuwanno ${ }^{1}$, Maitree Suttajit ${ }^{3}$, Sartjin Peerajan ${ }^{2}$, Chaiyavat Chaiyasut ${ }^{1 *}$ \\ ${ }^{1}$ Department of Pharmaceutical sciences, Faculty of Pharmacy, Chiang Mai University, Chiang Mai 50200, Thailand. ${ }^{2}$ Health Innovation Institute, Chiang \\ Mai 50200, Thailand. ${ }^{3}$ School of Medical Science, University of Phayao, Phayao 56000, Thailand.
}

\begin{tabular}{l} 
ARTICLE INFO \\
\hline Article history: \\
Received on: 02/11/2015 \\
Revised on: 23/12/2015 \\
Accepted on: 09/01/2016 \\
Available online: 27/02/2016 \\
\hline Key words: \\
Perilla frutescens, Pre- \\
treatment, lipase, Tocols, \\
Metabolic syndrome.
\end{tabular}

\begin{abstract}
Perilla frutescens (Nga-Mon) is an annual herbaceous plant, reported for its antioxidant, anti-allergic, antiinflammatory and neuroprotective properties. The current study was conducted to compare the different pretreatment techniques followed by hexane extraction for perilla seed oil and its pharmaceutical values. There are no significant differences in the yield of seed oil after pre-treatments except sonication. All the pre-treatments diminish the endogenous lipase activity, peroxidation and degradation of the oil. Fatty acid content analysis revealed that the nutrient quality, with respect to fatty acid content, of perilla seed was not compromised with any of the pre-treatments of current study. The results of $\alpha$-amylase, $\alpha$-glucosidase and protein glycation inhibition assays suggested that tested perilla seed oils are pharmaceutical candidate for the treatment of carbohydrate related diseases, especially for diabetes. Selection of appropriate pre-treatment strategies will helps to extract the perilla seed oil without any compromise in its quality. The current study suggested that moist heat with pressure can be an appropriate pre-treatment method for perilla seed oil extraction.
\end{abstract}

\section{INTRODUCTION}

Perilla frutescens (L.) Britton is an annual herbaceous plants used to gourmet food and as a traditional medicine in Asian countries. It's widely cultivated throughout the northern part of Thailand. The perilla seed is an alternative plant source of polyunsaturated fatty acids, phenolic compounds and natural antioxidants. The seed is rich source of the omega-3 (alphalinolenic acid, ALA), omega-6 (linoleic acid) and omega-9 fatty acid (oleic acid) (Gunstone, 1994). Recent reports have focused on the constituents of perilla leaf and seeds that are responsible for its antioxidant, antiallergic, anti-inflammatory and neuroprotective properties (Kim and Kim, 2009). Perilla oil contains large quantities of $n-3$ polyunsaturated fatty acids that include alpha-linolenic acid (omega-3 fatty acid), which have been reported to regulate glucose metabolism, and serum lipid

\footnotetext{
* Corresponding Author

Chaiyavat Chaiyasut, Department of Pharmaceutical sciences, Faculty of Pharmacy, Chiang Mai University, Chiang Mai 50200, Thailand Email:chaiyavat@gmail.com
}

concentrations in rats (Ide et al., 1996; Takahashi and Ide, 2000). Perillaldehyde of perilla exhibited anti-carcinogenic effect in PC12 cells (rat pheochromocytoma cell line) (Boon et al., 2000) and antidepressant-like effect by regulating the olfactory nervous system in mice (Ito et al., 2011). Perillaldehyde have been reported for its use in preservation of fruits, enhances the antioxidant activity and reduces the decay of blueberries (Wang et al., 2008) and Chinese bayberries (Jin et al., 2012).

Few in vitro studies have reported that perillyl alcohol (Bardon et al., 2002; Elegbede et al., 2003) and perillic acid (Bardon et al., 1998; Boon et al., 2000; Bardon et al., 2002) exhibited anti-cancer properties in cell lines. The addition of Perilla oil with Aruncus dioicus extract improved the total $\alpha$ glucosidase inhibitory activity (Ahn et al., 2014).

The information about anti-diabetic nature of perilla oil is very limited. Rendering, mechanical pressing and using a solvent extraction are the general extraction techniques followed for edible oil production (Kiple and Ornelas, 2000). Rendering is often referred to as a traditional method (Ketaren, 1986) and mechanical pressing is more popular for large-scale production until the solvents came for responsibility (Matthaus, 2008). 
At present, edible oils were subjected to different processes like degumming, neutralizing, bleaching and deodorizing to produce oil with good quality consistency and the quality further improved by removal of some unwanted components from oil either physical or chemical separation (McWilliams, 2001). Each and every technique has its own merits and demerits like rendering is ineffective in large scale production but the product processed with little or no chemicals, made this method as eco-friendly and healthy. People have followed different extraction techniques to recover vegetable oil (Febrianto and Yang, 2011), but still more detailed research is needed to increase the quality and quantity of the product. Even though previous literatures (Jung et al., 2012; Li et al., 2014) are available about perilla oil extraction, there is no adequate information about the pre-treatment methods and their effect on extraction yield, quality of seed oil, bioactive compounds and bioactivities of the perilla seed oil. Since the extraction procedure for obtaining perilla seed oil should not compromise any features of its natural medicinal traits, the current study was conducted to compare the different pre-treatment techniques followed by hexane extraction for perilla seed oil and to evaluate the anti-diabetic properties of extracts.

\section{MATERIALS AND METHODS}

\section{Pre-treatments}

P. frutescens (L.) Britton or Perilla seeds were purchased from The Royal Project, Thailand and subjected to different pretreatments and extraction method for extracting oil. Briefly, high quality perilla seeds were subjected to pre-treatment with microwave power (at 600 watts for $5 \mathrm{~min}$ of radiation), moist heat (10 min), moist heat with pressure (at $15 \mathrm{lbs}$ for $10 \mathrm{~min}$ ), sonication (at $120 \mathrm{~Hz}$ for $60 \mathrm{~min}$ ) and dry heat (at $100{ }^{\circ} \mathrm{C}$ for 10 min). Time and specifications for the pre-treatment of perilla seed was based on the unpublished data of our previous work and samples were coded for ease revealing purpose (Table 1).

\section{Extraction}

As mentioned earlier, the present study was employed to compare the pre-treatment of perilla seed followed by solvent extraction technique for its quality and quantity. For the extraction, pre-treated perilla seeds were mixed with hexane in 1:10 ratio (25 g perilla seed: $250 \mathrm{~mL}$ hexane; based on unpublished data) and the mixture was incubated at $40{ }^{\circ} \mathrm{C}$ for 30 min with agitation at 150 rpm (Standardized extraction condition, unpublished data). After incubation, the solution was filtered through $0.45 \mu \mathrm{m}$ membrane and the filtrate evaporated at $50{ }^{\circ} \mathrm{C}$ under reduced pressure and the obtained crude perilla seed oil samples were stored at $-20{ }^{\circ} \mathrm{C}$ until use.

\section{Preparation of the perilla seed extracts}

Perilla seeds were subjected to lipase and lipoxygenase enzyme deactivation process by following treatments 1 . Microwave heat at 600 watts for $5 \mathrm{~min}, 2$. Moist heat for $10 \mathrm{~min}$,
3. Moist heat with pressure at $15 \mathrm{lbs}$ for $10 \mathrm{~min}, 4$. Sonication at $120 \mathrm{~Hz}$ for $60 \mathrm{~min}$, and 5. Dry heat at $100{ }^{\circ} \mathrm{C}$ for $10 \mathrm{~min}$. After treatments, perilla seeds were mashed with the help of blender. Then seeds were grained with hexane (1:10 ratio) at RT for $24 \mathrm{~h}$. Then the solution was incubated at $40{ }^{\circ} \mathrm{C}$ for 30 min with shaking at the speed of $150 \mathrm{rpm}$.

The extractions were further processed for removal of hexane by rotary evaporator (Rotavapor RE120, Buchi, Switzerland) at $50{ }^{\circ} \mathrm{C}$. Extracts were measured for its yield calculation and flushed with nitrogen gas. The oil samples were stored at $-80{ }^{\circ} \mathrm{C}$ in an amber bottle. Percentage of perilla seed oil yield can be calculated as follows.

Yield of seed extract $(\%)=($ Oil extract from seeds $(\mathrm{g}) /$ Initial weight of seeds $(\mathrm{g})) \times 100$

\section{Lipase activity assay}

Lipase activity was measured by following procedure. Substrate solution was prepared by mixing $0.2 \mathrm{~mL}$ of solution A (40 mg of $p$-Nitro Phenyl-Laurate ( $p$ NPL) dissolved in $12 \mathrm{~mL}$ of isopropanol) and $3 \mathrm{~mL}$ of solution $\mathrm{B}(0.4 \mathrm{~g}$ of Triton $\mathrm{X}-100$ and $0.1 \mathrm{~g}$ gum arabic were dissolved in $90 \mathrm{~mL}$ of $100 \mathrm{mM}$ phosphate buffer $\mathrm{pH}$ 7.0). This emulsion was stable for $1 \mathrm{~h}$ at RT. $400 \mu \mathrm{L}$ of sample was mixed with $6.4 \mathrm{~mL}$ of substrate solution and the mixture was incubated at $35^{\circ} \mathrm{C}$ for $20 \mathrm{~min}$ in a shaking incubator. The reaction was terminated by boiling for $5 \mathrm{~min}$.

Then clear solution was collected by centrifugation at $6,000 \mathrm{rpm}$ for $15 \mathrm{~min}$ and the absorbance of the clear supernatant was measured at $410 \mathrm{~nm}$. One unit (U) of enzyme activity was defined as the amount of enzyme required for the liberation of 1 $\mu$ mol $p$ NPL per minute under the assay conditions. Amount of lipase in the sample was calculated by using standard curve of $p$ nitrophenol.

The enzyme activity was calculated as Enzyme $(\mathrm{U} / \mathrm{mL})=$ A x 17(dilution factor, volume of substrate emulsion / volume of sample)

\section{Tocols analysis}

The non-polar fraction was used to measure tocotrienols and tocopherols by reversed-phase HPLC using fluorescence detector according to Pengkumsri et al. (2015). All samples were measured in triplicate.

\section{Total fatty acid analysis}

All the samples were blended and $3 \mathrm{~g}$ of sample was mixed with $9 \mathrm{~mL}$ of dichloromethane: methane $(2: 1 \mathrm{v} / \mathrm{v})$. Then mixture was vortexed for $1 \mathrm{~h}$ with 15 min intervals and filtered through whatman no. 1 filter paper. $0.1 \mathrm{M} \mathrm{KCl}$ was mixed with filtrate ( $20 \%$ of total volume) and centrifuged at 2,000 rpm for $10 \mathrm{~min}$. Upper layer of the solution was discarded. Then $200 \mu \mathrm{L}$ of samples were mixed with $2 \mathrm{~mL}$ of methanol: hexane $(4: 1 \mathrm{v} / \mathrm{v})$ and $200 \mu \mathrm{L}$ of acetyl chloride in screw cap tube. Samples were heated at $100{ }^{\circ} \mathrm{C}$ with intermediate vortexing and cooled at room temperature. Then $5 \mathrm{~mL}$ of $6 \% \mathrm{~K}_{2} \mathrm{CO}_{3}$ was added, vortexed and 
centrifuged at 1,000 rpm for $5 \mathrm{~min}$. Upper layer was collected for gas chromatography (GC-2010+AOC20i+s, shimadzu) analysis equipped with DB-23 column $(30 \mathrm{~m} \times 0.25 \mathrm{~nm})$ and Flame ionization detector. The samples were injected via split injector port (split ratio 50:1).

Percentage of fatty acid was calculated as follows.

Percentage of fatty acid $(\%)=$ Area under the curve $\times 100 /$ Total area of all fatty acid

\section{Determination of Peroxide value}

The peroxide value of the perilla seed oil was measured according to United States Pharmacopeia 37. Briefly, $1 \mathrm{~g}$ of oil samples were mixed with $0.5 \mathrm{~mL}$ of saturated potassium iodide solution and $20 \mathrm{~mL}$ of acetic acid: chloroform (3: 2) solution. Then the solution was boiled for $30 \mathrm{sec}$ and mixed with $20 \mathrm{~mL}$ of $5 \%$ potassium iodide solution and $25 \mathrm{~mL}$ of distilled water.

The solution was titrated against $0.002 \mathrm{~N}$ sodium thiosulfate containing 2-3 drops of starch as indicator until disappearance of blue color. Same preparation without oil sample was served as blank. The peroxide value was represented as milliequivalent of oxygen per kilogram of oil $(\mathrm{mEq} / \mathrm{Kg})$ and calculated by $(\mathrm{mEq} / \mathrm{kg})=2 \times(\mathrm{A}-\mathrm{B}) /$ oil sample $(\mathrm{g})$. Where, A and $\mathrm{B}$ denote volume of sodium thiosulfate $(\mathrm{mL})$ in test and blank, respectively (Firestone, 2000).

\section{Determination of acid value}

The acid value is representative of triglyceride content in oil sample that are an indicator of degradation and rancidity of oil. The acid value of the perilla seed oil was measured according to United States Pharmacopeia 37. Briefly, $50 \mathrm{~mL}$ of $95 \%$ ethanol with $0.5 \mathrm{~mL}$ of $1 \%$ phenolphthalein was titrated with $0.1 \mathrm{M}$ potassium hydroxide to obtain the neutral solution. Then $2 \mathrm{~g}$ of oil samples were added and continued the titration until the appearance of pink color. Same preparation without oil sample was served as blank.

The acid value was represented as $\mathrm{mg}$ of potassium hydroxide equivalent per gram of oil $(\mathrm{mEq} / \mathrm{Kg})$ and calculated by $(\mathrm{mg} \mathrm{KOH} / \mathrm{g}$ oil $)=\mathrm{V} \times 5.61 / \mathrm{W}$. Where, $\mathrm{V}$ and $\mathrm{W}$ denote the volume of potassium hydroxide $(\mathrm{mL})$ and weight of oil $(\mathrm{g})$, respectively and 5.61 is a constant value (equivalence of mass of $0.1 \mathrm{M} \mathrm{KOH})$.

\section{$\alpha$ - amylase enzyme inhibition assay}

The ability of $\alpha$ - amylase enzyme inhibition by perilla seed oil was estimated. Briefly, $500 \mu \mathrm{L}$ of sample was mixed with $500 \mu \mathrm{L} \alpha$ - amylase solution $(0.5 \mathrm{unit} / \mathrm{mL}$ prepared in sodium phosphate buffer pH6.9) and incubated at $25{ }^{\circ} \mathrm{C}$ for $10 \mathrm{~min}$. After the incubation period, $500 \mu \mathrm{L}$ of $0.5 \%$ starch solution prepared in sodium phosphate buffer pH 6.9 was added and incubated at $25{ }^{\circ} \mathrm{C}$ for $10 \mathrm{~min}$ after appropriate mixing.

Then $1 \mathrm{~mL}$ of DNS solution was added and incubated in boiling water bath for $10 \mathrm{~min}$. After incubation, $5 \mathrm{~mL}$ of deionized water was added and the absorbance was measured at $540 \mathrm{~nm}$ by a multimode spectrophotometer (DTX 880, Beckman Coulter Inc., UK) (Kazeem et al., 2013).

\section{$\alpha$ - glucosidase enzyme inhibition assay}

The ability of $\alpha$ - glucosidase enzyme inhibition by perilla seed oil was estimated by the modified method of Kusirisin et al. (2009). Briefly, $100 \mu \mathrm{L}$ of sample was mixed with $100 \mu \mathrm{L} \alpha$ glucosidase solution $(5 \mathrm{unit} / \mathrm{mL}$ prepared in $0.1 \mathrm{M}$ phosphate buffer pH6.9) and incubated at $37{ }^{\circ} \mathrm{C}$ for $10 \mathrm{~min}$. After the incubation period, $500 \mu \mathrm{L}$ of $0.1 \%$ starch solution prepared in 0.1 $\mathrm{M}$ phosphate buffer $\mathrm{pH} 6.9$ was added and incubated at $37{ }^{\circ} \mathrm{C}$ for $10 \mathrm{~min}$ after appropriate mixing. Then $1 \mathrm{~mL}$ of DNS solution was added and incubated in boiling water bath for $10 \mathrm{~min}$. After incubation, $5 \mathrm{~mL}$ of deionized water was added and the absorbance was measured at $540 \mathrm{~nm}$ by a multimode spectrophotometer (DTX 880, Beckman Coulter Inc., UK)

\section{Protein glycation inhibition}

Perilla seed oil was evaluated also for protein glycation inhibition ability by the modified method of Kusirisin et al. (2009). Briefly, $200 \mu \mathrm{L}$ of BSA $(65 \mathrm{mg} / \mathrm{mL}$ prepared in $50 \mathrm{mM}$ phosphate buffer $\mathrm{pH}$ 6.9) was mixed with $100 \mu \mathrm{L}$ of glucose solution (14.64 mg/mL of $50 \mathrm{mM}$ phosphate buffer $\mathrm{pH}$ 6.9) and $400 \mu \mathrm{L}$ of fructose solution $(14.64 \mathrm{mg} / \mathrm{mL}$ of $50 \mathrm{mM}$ phosphate buffer pH6.9) followed by $200 \mu \mathrm{L}$ of perilla seed oil and $100 \mu \mathrm{L}$ of sodium azide ( $2.6 \mathrm{mg} / \mathrm{mL}$ of $50 \mathrm{mM}$ phosphate buffer $\mathrm{pH}$ 6.9) was added and incubated at $37{ }^{\circ} \mathrm{C}$ for 1 week. After the incubation, the reaction was measured at fluorescence excitation $350 \mathrm{~nm}$, emission $450 \mathrm{~nm}$.

\section{Statistical analysis}

The enzyme inhibitory assays were analyzed in triplicate and data is reported as mean \pm SD. The statistical significance of the data was determined by one way ANOVA. Duncan's new multiple range test determined significant differences, at the 95\% confidential level $(p<0.05)$ using statistical SPSS software version 17.0 (SPSS Inc, Chicago, U.S.A).

\section{RESULTS AND DISCUSSION}

\section{Pre-treatment and Extraction}

The current study employed the different pre-treatment protocol to destroy the lipase and pre-treated perilla seeds were subjected for hexane extraction techniques as detailed in materials and methods section and tabulated (Table 1). The yield of perilla seed oil from different procedure has been calculated as mentioned in materials and methods section. The highest yield $(59.9 \%)$ was obtained from the procedure by which the raw perilla seeds were subjected to microwave heat at 600 watt for $5 \mathrm{~min}$ followed by hexane extraction, whereas least amount $(50.6 \%)$ of product was obtained from the procedure by which the raw perilla seeds were subjected to sonication at $120 \mathrm{~Hz}$ for $60 \mathrm{~min}$ and hexane extraction. The comparison of mode of pre-treatment procedures like microwave heat, moist heat, moist heat+ pressure, dry heat 
and sonication suggested that there is no immense difference in the yield of seed oil except sonication because sonication reduces the yield (Table 1) compared to untreated control. The extracted perilla seed oils were found as clear or slightly turbid liquids with pale yellow to brown in color, viscous and had specific odor. The results suggested that any tested pre-treatments does not hinder the quantity of the oil, significantly.

Table 1: Percentage of yields and coding of collected perilla seed extracts through hexane extraction in the current investigation with different pretreatment methods.

\begin{tabular}{clll}
\hline $\begin{array}{c}\text { S. } \\
\text { No }\end{array}$ & \multicolumn{1}{c}{ Pre-treatment } & $\begin{array}{c}\text { Sample } \\
\text { code }\end{array}$ & $\begin{array}{c}\text { \% of yield } \\
\text { (Mean } \pm \text { SD) }\end{array}$ \\
\hline 1 & Untreated & UT. Hex & $52.2 \pm 1.2$ \\
2 & Microwave heat at 600 watts for $5 \mathrm{~min}$ & MV. Hex & $59.9 \pm 0.9$ \\
3 & Moist heat for $10 \mathrm{~min}$ & MH. Hex & $55.0 \pm 0.8$ \\
4 & Moist heat with pressure at 15 lbs for 10 & MP. Hex & $52.6 \pm 1.1$ \\
& min & & \\
5 & Sonication at $120 \mathrm{~Hz}$ for $60 \mathrm{~min}$ & SN. Hex & $50.6 \pm 1.0$ \\
6 & Dry heat at $100^{\circ} \mathrm{C} \mathrm{for} 10 \mathrm{~min}$ & DH. Hex & $56.8 \pm 1.3$ \\
\hline
\end{tabular}

\section{Lipase inhibition}

Rationale of pre-treatment of perilla seed was to inhibit or inactivate the endo-enzyme lipase, which can drop off the quality and quantity of fatty acid content of perilla seed upon extraction. Lipase activity of the extracted oil samples were assessed. The pre-treatments reduce the endo-enzyme lipase activity when compared to untreated sample. Higher the inhibition of lipase activity was observed in moist heat with pressure treatments. Next to this, moist heat and dry heat treatments suppresses the endo-lipase activity (Fig. 1). This result suggested that pre-treatments protect the valuable constituents of perilla seed oil from lipase mediated degradation.

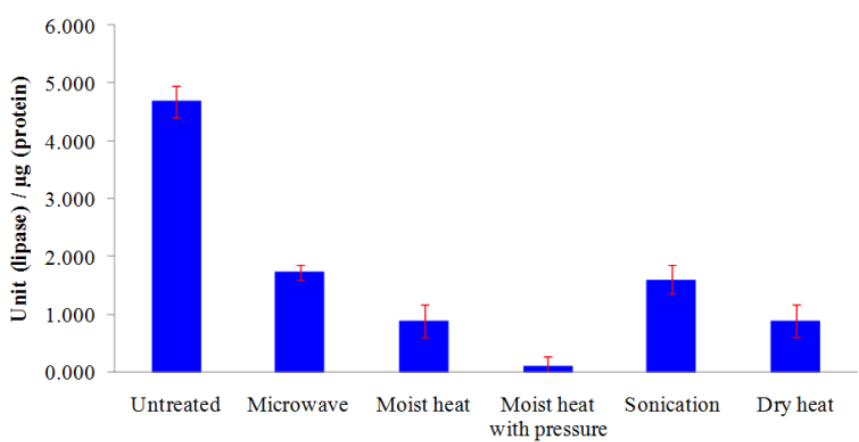

Fig. 1: Analysis of endo-lipase activity of perilla seed oil after pre-treatments. Values were represented as unit of lipase per $\mu \mathrm{g}$ of protein.

\section{Tocols}

Tocols (tocopherols and tocotrienols) are natural antioxidants present in many grains. Some tocols content was analyzed in pre-treated perilla oils. Only $\delta$-Tocopherol and $\gamma$ Tocopherol was detected in perilla oil with irrespective of pretreatments. Other tocols like $\delta$-tocotrienol, $\beta$-tocotrienol, $\gamma-$ tocotrienol, $\alpha$-tocotrienol, $\beta$-tocopherol and $\alpha$-tocopherol were not detected in perilla oil (Fig. 2A, B). Regarding $\delta$-tocopherol content $(129.98$ to $165.12 \mu \mathrm{g} / \mathrm{mL})$, no extreme differences was observed between different pre-treated samples. Whereas, the $\gamma$ - tocopherol content was found as higher in the samples subjected to dry heat $(6,388.85 \pm 72.19 \mu \mathrm{g} / \mathrm{mL})$ compared to untreated samples $(3,058.53 \pm 152.82 \mu \mathrm{g} / \mathrm{mL})$ and almost all the pre-treated samples displayed high content of $\gamma$-tocopherol than untreated samples (Fig. 2C). A previous study reported about tocol content of perilla seed with high content of $\gamma$-Tocopherol $(37.4 \pm 4.8 \mathrm{mg} / 100 \mathrm{~g}$ of perilla) and no $\alpha$-Tocotrienol $\gamma$-Tocotrienol content was detected (Adhikari et al., 2008). The results of present study clearly suggested that pre-treatments prevent the degradation of $\gamma$ tocopherol during processing of perilla seed oil production.
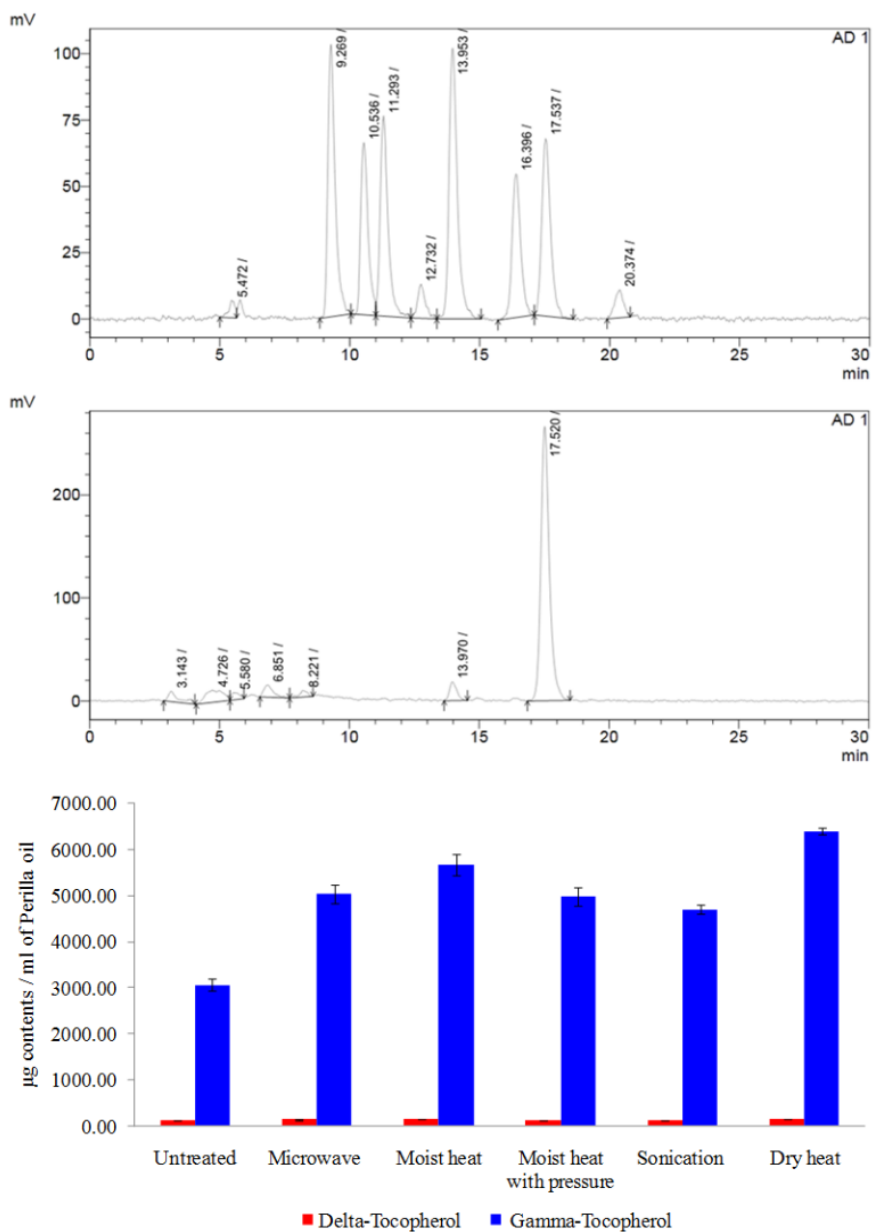

Fig. 2: Tocol content of perilla seed oils. A. HPLC chromatogram of tocols standards. B. Representative chromatogram of HPLC of perilla oil. C. Graph showing the tocol content of pretreated perilla seed oil samples. High content of $\gamma$-tocopherol was detected in all the samples.

\section{Total fatty acid}

Perilla seed oils were analyzed to assess the differences in the composition and content of essential fatty acids. AlphaLinolenic acid (ALA, $60 \%$ ), linoleic acid (LA, $16 \%$ ), oleic acid (OA, $\sim 13 \%$ ), palmitic acid (PA, $\sim 6 \%$ ), and stearic acid (SA, $\sim 3 \%$ ) are the major constituent of all tested perilla seed oils. Cis-11,14,17-eicosatrienoic acid and behenic acid was not detected in moist heat with pressure treated samples. Fatty acid analysis of perilla oil suggested that pre-treatment strategies will not affect the quality of the oil with respect to essential fatty acid content. 
Table 2: Analysis of fatty acid content of Perilla seed oil extracted through hexane with different pre-treatments.

\begin{tabular}{|c|c|c|c|c|c|c|c|}
\hline \multirow{2}{*}{$\begin{array}{c}\text { S. } \\
\text { No. }\end{array}$} & \multirow{2}{*}{ Name of the fatty acids } & \multicolumn{6}{|c|}{ Fatty acid content $(\%)$} \\
\hline & & Untreated & Microwave & Moist heat & Moist heat with pressure & Sonication & Dry heat \\
\hline 1 & Lauric acid (C12:1) & 0.01 & 0.01 & 0.01 & 0.01 & 0.01 & 0.01 \\
\hline 2 & Myristic acid (C14:0) & 0.03 & 0.03 & 0.03 & 0.03 & 0.03 & 0.04 \\
\hline 3 & Palmitic acid (C16:0) & 6.55 & 6.57 & 6.56 & 6.71 & 6.5 & 6.9 \\
\hline 4 & Palmitoleic acid (C16:1) & 0.07 & 0.07 & 0.07 & 0.07 & 0.07 & 0.08 \\
\hline 5 & Heptadecanoic acid (C17:0) & 0.05 & 0.04 & 0.04 & 0.04 & 0.04 & 0.04 \\
\hline 6 & Stearic acid (C18:0) & 3.37 & 3.39 & 3.39 & 3.42 & 3.4 & 3.4 \\
\hline 7 & Oleic acid (C18:1 n-9 cis) & 13.02 & 13.04 & 12.96 & 12.96 & 12.98 & 13.16 \\
\hline 8 & Linoleic acid (C18:2 n-6 cis) (omega-6) & 16.04 & 16.17 & 16.12 & 16.17 & 16.14 & 16.06 \\
\hline 9 & $\alpha$-Linolenic acid (C18:3n-3) (omega-3) & 60.39 & 60.2 & 60.34 & 60.09 & 60.36 & 59.81 \\
\hline 10 & Arachidic acid (C20:0) & 0.2 & 0.21 & 0.2 & 0.2 & 0.21 & 0.21 \\
\hline 11 & Cis-11-Eicosenoic acid (C20:1 n-9) & 0.11 & 0.11 & 0.11 & 0.12 & 0.1 & 0.11 \\
\hline 12 & Cis-11,14-Eicosadienoic acid (C20:2 n-6 ) & 0.08 & 0.09 & 0.09 & 0.09 & 0.08 & 0.08 \\
\hline 13 & Cis-11,14,17-Eicosatrienoic acid (C20:3 n-6) & 0.06 & 0.05 & 0.05 & ND* & 0.05 & 0.05 \\
\hline 14 & Behenic acid (C22:0) & 0.03 & 0.04 & 0.03 & ND* & 0.04 & 0.04 \\
\hline
\end{tabular}

*ND means not detected .

High content of ALA and LA was identified in tested oils (Table 2). Dietary supplementation is the sole source of ALA for human. The advisable average daily ALA consumption is greater than $1.5 \mathrm{~g}$ (Gebauer et al., 2006). Some studies suggested that ALA intakes reduce the risk of cardiovascular diseases (CVD) with some controversies (Harris, 2008; Wang et al., 2006; Brouwer et al., 2004). An interaction between dietary ALA intake, and cardiovascular health in humans was reviewed (Geleijnse et al., 2010). LA reduces the risk of coronary artery disease (CAD), whereas ALA inversely related to the risk of CAD (Djousse et al., 2001). Some of the clinical trials suggested that high LA consumption leads to harmful effects on long-term health (Vos and Cunnane, 2003). Low amount of LA ( 16\%) was detected in comparision to ALA $(\sim 60 \%)$ in perilla seed oil (Table 2$)$. OA diminish the negative effects of inflammatory cytokines (Vassiliou et al., 2009). OA has been estimated to reduce coronary heart disease risk by 20-40 \% and CVD. Recommended level of OA intakes and other detailed health benefits were documented (Lopez -Huertas, 2010).

Saturated fatty acids (PA, SA) were detected in considerable level in perilla seed oils. PA and SA are some of the main fatty acids present in animals, vegetables and, human milk fats. Several controversies are there about health and adverse impact of PA and SA on human health, particularly about role of PA in CVD and carcinogenicity (Hunter et al., 2010; Fattore and Fanelli, 2013). Other than these fatty acids, some others were detected in perilla seed oil samples (Table 2). Even though, PA, SA and other saturated fatty acids are there in perilla, rich amount of almost $89 \%$ of fatty acid content is made up of polyunsaturated and monounsaturated fats (ALA, LA, OA). Thus the nutrient quality, with respect to fatty acid content, of perilla seed was not compromised with any of the pre-treatments of current study.

\section{Peroxide and acid values}

The peroxide and acid values for pre-treated and untreated perilla seed oil samples were assessed (Fig. 3). The results suggested that pre-treatments minimize the rate of lipid peroxidation and degradation of perilla seed oil. As per the Thai
Ministry of Public Health Notification (2000), oil and oil based products should not have the peroxide value more than 10 and acid value more than 4.00. The moist heat with pressure treatment was found as an effective pre-treatment strategy (Peroxide value: 6.56 $\pm 0.37 \mathrm{mEq} / \mathrm{Kg}$ of oil; Acid value: $3.52 \pm 0.39 \mathrm{mg} \mathrm{KOH} / \mathrm{g}$ of oil) to inactivate the lipase in perilla oil. Except microwave treatment, other pre-treatment strategies are effective with respect to the peroxide values of perilla oil (Fig. 3A). Whereas, only moist heat with pressure and dry heat methods have showed positive impact on quality of perilla oil with respect to acid values (Fig. 3B). In general, all the pre-treatments are effective when compared to untreated samples.

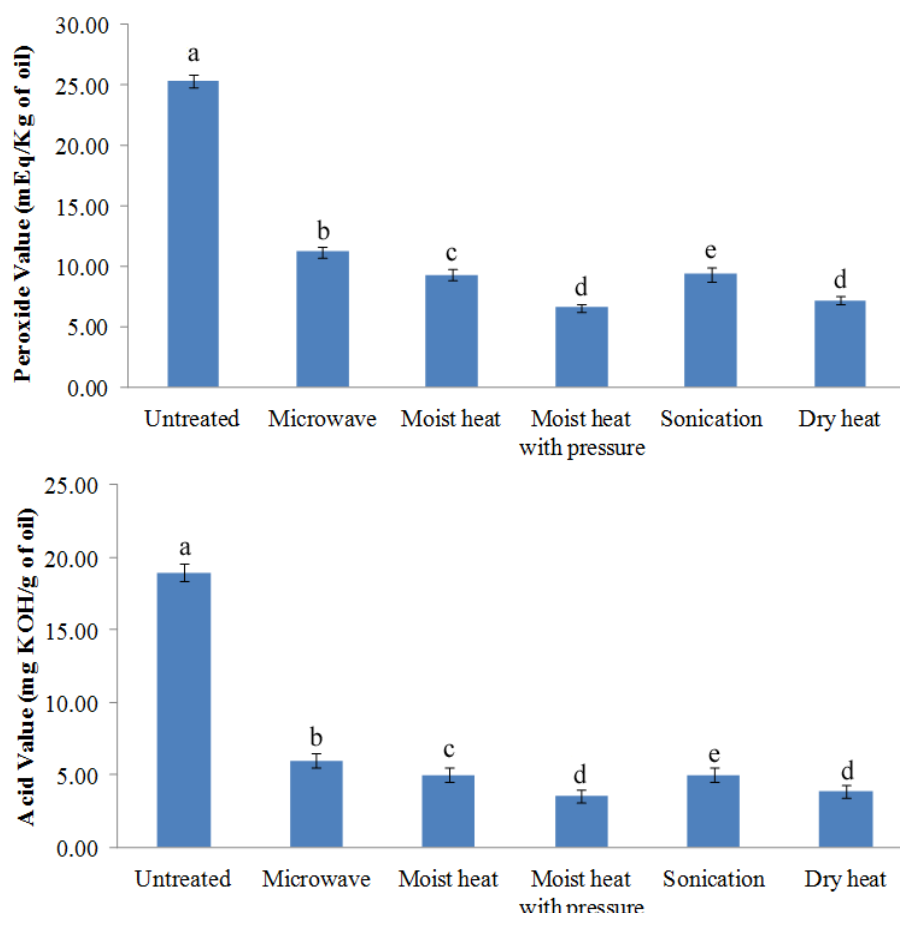

Fig. 3: Peroxide (A) and acid (B) values of pre-treated perilla seed oil. Alphabets (a-e) of the respective bars indicate the significant difference between pre-treatments. 


\section{In vitro enzyme inhibitory activity of perilla seed oil}

$\alpha$ - amylase, $\alpha$ - glucosidase and protein glycation inhibition ability of perilla seed oil was assessed. Inhibition of $\alpha$ amylase is considered as one of the approach to treat disorders related to carbohydrate uptake, such as diabetes and obesity, and periodontal diseases. Alpha-glucosidase, another candidate involved in carbohydrate synthesis and breakdown, have role in diabetes, viral infection and, even cancer. Acarbose, voglibose, and miglitol are clinically used anti-diabetic agents, which suppresses the $\alpha$-glucosidase activity (Liu et al., 2011). The results of the study displayed that next to untreated sample $(43.03 \%)$, pre-treatment by dry heat at $100{ }^{\circ} \mathrm{C}$ for $10 \mathrm{~min}$ followed by hexane extracted oil shows highest (42.42\%) inhibition during $\alpha$ - amylase inhibition assay, whereas microwaved samples displayed the minimum activity (17.20\%) (Fig. 4). In case of $\alpha$ - glucosidase inhibitory assay, moist heat with pressure and microwaved samples displayed the highest activity $(10.01 \%)$ and sonicated sample shows minimum activity $(6.77 \%)$ (Fig. 5). Natural sources, especially plants, are the most promising supplier of chemical constituents with $\alpha$ - amylase inhibiting ability. Sales et al., (2012) reviewed about $\alpha$ - amylase inhibiting nature of plant crude extracts and compounds, which can be used as pharmaceutical candidates. The results of current study also suggested that pre-treatments enhances the $\alpha$ - amylase inhibiting nature of perilla oil (Fig. 4).
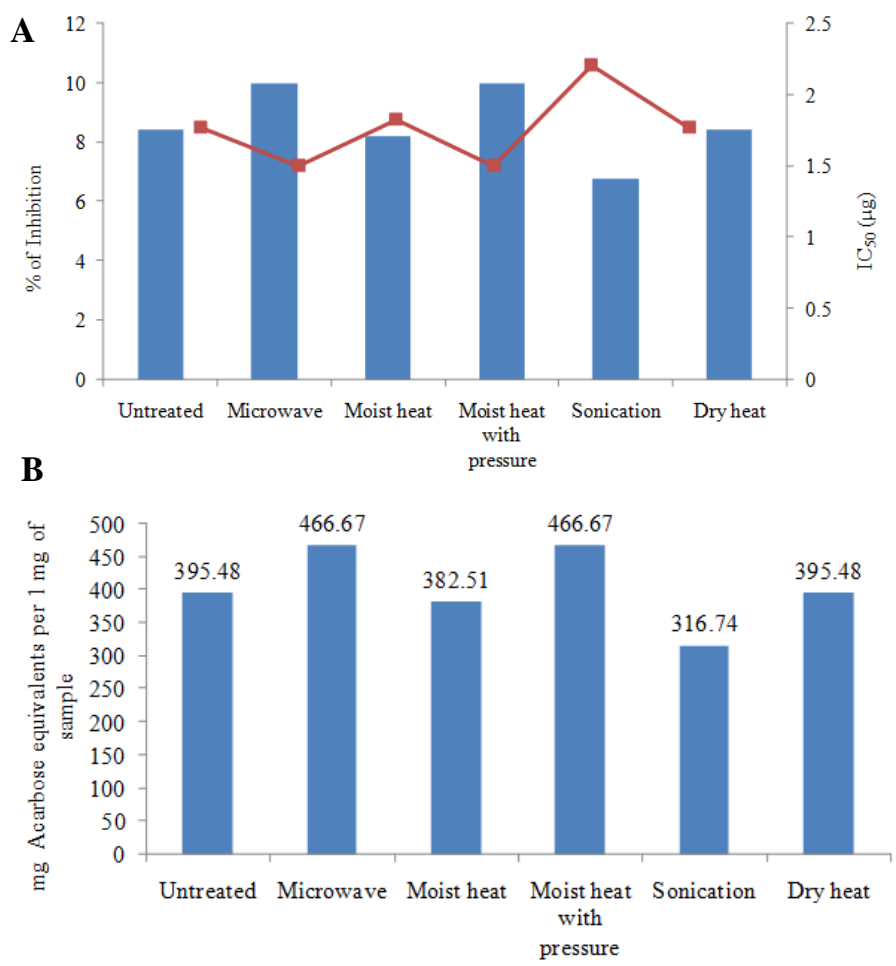

Fig. 4: $\alpha$ - amylase inhibition assay for perilla seed oil samples and $\mathrm{IC}_{50}$ concentration of samples for the inhibition was also represented as line graph.

Protein glycation is a non-enzymatic reaction resulting in the formation of advanced glycation end products after several processes like reaction between reducing sugar and free amino groups and oxidation. Previous studies have revealed that protein glycation have critical role in pathogenesis of diabetes, atherosclerosis, end-stage renal disease, and neurodegenerative diseases (Jriyapamornkoon et al., 2013; Ahmed, 2005). Evaluation of protein glycation inhibition ability suggested that microwaved sample having highest inhibitory activity for protein glycation $(22.83 \%)$ and moist heat with pressure treated sample shows lowest activity (10.79) (Fig. 6). Moreover the $\mathrm{IC}_{50}$ concentration for $\alpha$ - amylase, $\alpha$-glucosidase and protein glycation inhibition found to be varied with pre-treatment protocols (Fig. 4, $5,6)$. These results suggested that tested perilla seed oils are best pharmaceutical candidate for the treatment of carbohydrate related diseases, especially for diabetes.
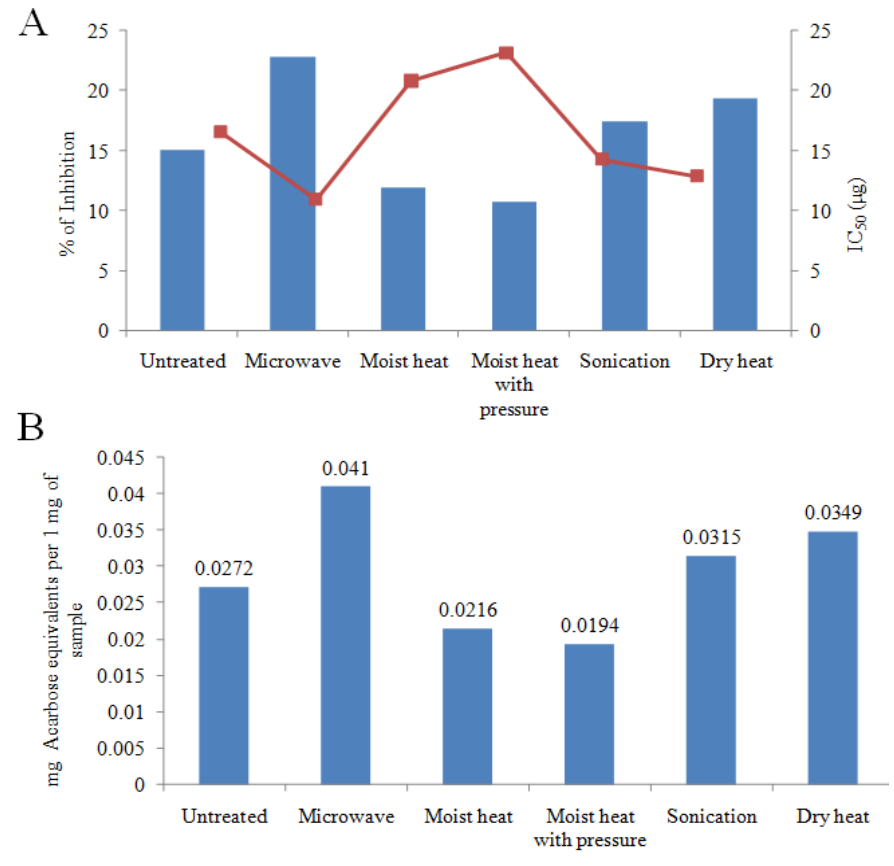

Fig. 5: A. $\alpha$-glucosidase inhibitory assay for perilla seed oil samples and $\mathrm{IC}_{50}$ concentration of samples for the inhibition was also represented as line graph. B. Acarbose, an anti-diabetic drug, equivalent of perilla oil was measured and represented as mg Acarbose equivalents per mg of oil.

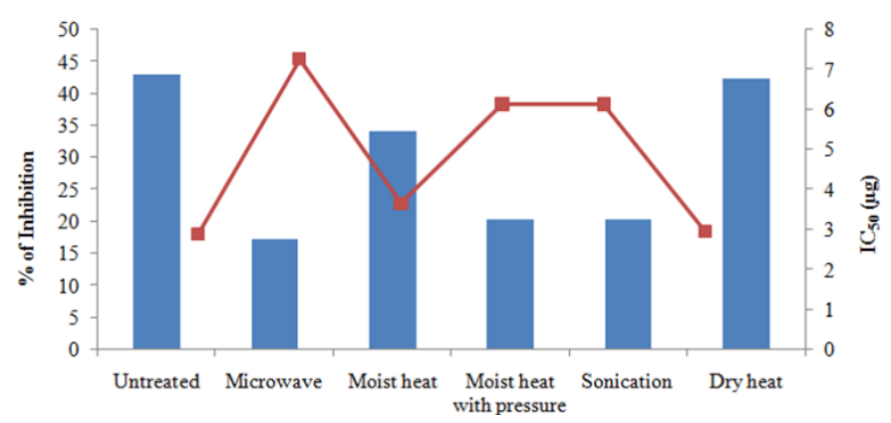

Fig. 6: A. Protein glycation inhibition profile of perilla seed oil samples and $\mathrm{IC}_{50}$ concentration of samples for the inhibition was also represented as line graph. B. Acarbose, an anti-diabetic drug, equivalent of perilla oil was measured and represented as mg Acarbose equivalents per mg of oil. 


\section{CONCLUSION}

The results of present study suggested that pre-treatments inhibits the endogenous lipase thereby it facilitates the safe recovery of perilla seed oil without any hindrance in its quality. The beneficiary bio-activities of the perilla oil were affected by pre-treatment strategies, even though quantity and quality of fatty acid composition was not affected more wisely. Every pretreatment have some positive and negative impact on the quality and character of the extracted oils. Thus, selection of appropriate pre-treatment strategies will help to achieve enhanced perilla seed oil with desired quality. The results of present study suggested that moist heat with pressure treatment was best method for extracting high quality perilla oil without any significant loss of pharmaceutical values.

\section{ACKNOWLEDGEMENTS}

Authors wish to thank Chiang Mai University, Thailand for the support by CMU research grant program. We gratefully acknowledge the instrumentation facility provided by Faculty of Pharmacy, Chiang Mai University, Thailand.

\section{REFERENCES}

Adhikari P, Hwang KT, Shin MK, Lee BK, Kim SK, Kim SY, Lee K, Kim SZ. Tocols in caneberry seed oils. Food Chem, 2008; 111: 687-690.

Ahmed N. Advanced glycation endproducts-role in pathology of diabetic complications. Diabetes Res Clin Pract, 2005; 67: 3-21.

Ahn H. Kim J. Kim J. Auh J. Choe E. In vitro $\alpha$-Glucosidase and Pancreatic Lipase Inhibitory Activities and Antioxidants of Samnamul (Aruncus dioicus) during Rehydration and Cooking. Food Sci Biotechnol, 2014; 23: 1287-1293.

Bardon S, Picard K, Martel P. Monoterpenes inhibit cell growth, cell cycle progression, and cyclin D1 gene expression in human breast cancer cell lines. Nutr Cancer, 1998; 32: 1-7.

Bardon S, Foussard V, Fournel S, Loubat, A. Monoterpenes inhibit proliferation of human colon cancer cells by modulating cell cycle-related protein expression. Cancer Lett, 2002; 181: 187-194.

Boon PJM, Van Der Boon D, Mulder GJ. Cytotoxicity and biotransformation of the anticancer drug perillyl alcohol in PC12 cells and in the rat. Toxicol Appl Pharmacol, 2000; 167: 55-62.

Brouwer IA, Katan MB, Zock PL. Dietary alpha-linolenic acid is associated with reduced risk of fatal coronary heart disease, but increased prostate cancer risk: a meta-analysis. J Nutr, 2004; 134: 919 922.

Djousse L, Pankow JS, Eckfeldt JH, Folsom AR, Hopkins PN, Province MA, Hong Y, Ellison RC. Relation between dietary linolenic acid and coronary artery disease in the National Heart, Lung, and Blood Institute Family Heart Study. Am J Clin Nutr, 2001; 74: 612-619.

Elegbede JA, Flores R, Wang RC. Perillyl alcohol and Perillaldehyde induced cell cycle arrest and cell death in BroTo and A549 cells cultured In vitro. Life Sci, 2003; 73: 2831-2840.

Fattore E, Fanelli R. Palm oil and palmitic acid: a review on cardio-vascular effects and carcinogenicity. Int J Food Sci Nutr, 2013; 64: 648-59.

Febrianto NA, Yang TA. Producing High Quality Edible Oil by using Eco-Friendly Technology: A Review. Adv J Food Sci Technol, 2011; 3: 317-326.
Firestone D. 2000. Oils and Facts. In official methods of Analysis of AOAC International. $17^{\text {th }}$ ed. Vol. II, AOAC International, Maryland, Chapter 41, pp. 1-69.

Gebauer SK, Psota TL, Harris WS, Kris-Etherton PM. N-3 fatty acid dietary recommendations and food sources to achieve essentiality and cardiovascular benefits. Am J Clin Nutr, 2006; 83: 1526S-1535S.

Geleijnse JM, Goede JD, Brouwer IA. Alpha-Linolenic Acid: Is It Essential to Cardiovascular Health. Curr Atheroscler Rep, 2010; 12: 359-367.

Gunstone FD, Harwood J, Padley FB. 1994. The Lipid? Handbook ( $2^{\text {nd }}$ ed.), Chapman and Hall, London.

Harris WS. Cardiovascular risk and alpha-linolenic acid: can Costa Rica clarify. Circulation, 2008; 118: 323-324.

Hunter JE, Zhang J, Kris-Etherton PM. Cardiovascular disease risk of dietary stearic acid compared with trans, other saturated, and unsaturated fatty acids: a systematic review. Am J Clin Nutr 2010; 91: 46-63.

Ide T, Murata M, Sugano M. Stimulation of the activities of hepatic fatty acid oxidation enzymes by dietary fat rich in $\alpha$-linolenic acid in rats. J Lipid Res, 1996; 37: 448-463.

Ito $\mathrm{N}$, Nagai $\mathrm{T}$, Oikawa $\mathrm{T}$, Yamada $\mathrm{H}$, Hanawa $\mathrm{T}$. Antidepressant-like effect of 1-Perillaldehyde in stress-induced depression-like model mice through regulation of the olfactory nervous system. Evid Based Complement Alternat Med, 2011; article no: 2011.

Jariyapamornkoon N, Yibchok-anun S, Adisakwattana S. Inhibition of advanced glycation end products by red grape skin extract and its antioxidant activity. BMC Complement. Altern Med, $2013 ; 13: 171$

Jin, P, Wu X, Xu F, Wang X, Wang J, Zheng Y. Enhancing antioxidant capacity and reducing decay of Chinese bayberries by essential oils. J Agric Food Chem, 2012; 60: 3769-3775.

Jung DM, Yoon SH, Jung MY. Chemical properties and oxidative stability of perilla oils obtained from roasted perilla seeds as affected by extraction methods. J Food Sci, 2012; 77: C1249-1255.

Kazeem MI, Adamson JO, Ogunwande IA. Modes of inhibition of $\alpha$-amylase and $\alpha$-glucosidase by aqueous extract of Morinda lucida Benth leaf. Biomed Res Int, 2013; 2013: 527570.

Ketaren, S. 1986. The Introduction to Food Fats and Oils. UI Press, Jakarta.

Kim M, Kim H K. Perilla Leaf Extract Ameliorates Obesity and Dyslipidemia Induced by High-Fat Diet. Phytother Res, 2009; 23: 1685-1690.

Kiple KF, Ornelas KC. 2000. The Cambridge World History of Food. Cambridge University Press, Cambridge.

Kusirisin W, Jaikang C, Chaiyasut C, NarongchaI P. Effect of polyphenolic compounds from Solanum torvum on plasma lipid peroxidation, superoxide anion and cytochrome P450 2E1 in human liver microsomes. Med Chem, 2009; 5: 583-588.

Li Y, Li D, Qi B, Rokayya S, Ma W, Liang J, Sui X, Zhang Y, Jiang L. Heating Quality and Stability of Aqueous Enzymatic Extraction of Fatty Acid-Balanced Oil in Comparison with Other Blended Oils. J Chem, 2014.

Liu M, Zhang W, Wei J, Lin X. Synthesis and $\alpha$ Glucosidase Inhibitory Mechanisms of Bis (2,3-dibromo-4,5dihydroxybenzyl) Ether, a Potential Marine Bromophenol $\alpha$ Glucosidase Inhibitor. Mar Drugs, 2011; .9: 1554-1565.

Lopez-Huertas E. Health effects of oleic acid and long chain omega-3 fatty acids (EPA and DHA) enriched milks. A review of intervention studies. Pharmacological Research, 2010; 61: 200-207

Matthaus B. Editorial: Virgin oils-the return of a long known product. Eur J Lipid Sci Technol, 2008; 110: 595-596.

Mc-Williams M.. 2001. Foods: Experimental Perspectives. Prentice Hall, New Jersey. 
Pengkumsri N, Chaiyasut C, Sivamaruthi BS, Saenjum C, Sirilun S, Peerajan S, Suwannalert P, Sirisattha S, Chaiyasut K, Kesika,P. The influence of extraction methods on composition and antioxidant properties of rice bran oil. Food Sci Technol, 2015; 35(3): 493-501.

Sales PM, Souza PM, Simeoni LA, Silveira D. $\alpha$-Amylase Inhibitors: A Review of Raw Material and Isolated Compounds from Plant Source. J Pharm Pharmaceut. Sci, 2012; 15: 141-183.

Takahashi Y, Ide T. Dietary n-3 fatty acids affect mRNA level of brown adipose tissue uncoupling protein 1, and white adipose tissue leptin and glucose transporter 4 in the rat. Br J Nutr, 2000; $84: 175-84$

Vassiliou EK, Gonzalez A, Garcia C, Tadros JH, Chakraborty G, Toney JH. Oleic acid and peanut oil high in oleic acid reverse the inhibitory effect of insulin production of the inflammatory cytokine TNF-alpha both In vitro and in vivo systems. Lipids Health Dis, 2009; 8: 25.

Vos E, Cunnane SC. Linolenic acid, linoleic acid, coronary artery disease, and overall mortality. Am J Clin Nutr, 2003; 77: 521523.
Wang C, Harris WS, Chung M, Lichtenstein AH, Balk EM, Kupelnick B, Jordan HS, Lau J. N-3 Fatty acids from fish or fish-oil supplements, but not alpha-linolenic acid, benefit cardiovascular disease outcomes in primary- and secondary- prevention studies: a systematic review. Am J Clin Nutr, 2006; 84: 5-17.

Wang CY, Wang SY, Chen C. Increasing antioxidant activity and reducing decay of blueberries by essential oils. J Agric Food Chem, 2008; 56: 3587-3592.

\section{How to cite this article:}

Sirilun S, Sivamaruthi BS, Pengkumsri N, Saelee M, Chaiyasut K, Tuntisuwanno N, Suttajit M, Peerajan S, Chaiyasut C. Impact of different pre-treatment strategies on the quality of fatty acid composition, tocols content and metabolic syndrome related activities of Perilla frutescens seed oil. J App Pharm Sci, 2016; 6 (02): 001-008. 